\title{
Introducing quality assurance into long term care for elderly people: a difficult and worthwhile process?
}

\author{
Yvonne Challiner
}

Improving quality of care in long term care homes could enhance the lives of many elderly people. Traditional inspection procedures, although preventing substandard care, have limited ability to increase residential quality of life. ${ }^{2}$ A new generation of quality assurance procedures has the potential to change everyday practice in homes: ${ }^{1}$ but the procedures also potentially pose problems. They require staff, who are already stretched, to set aside time to examine what they actually do. The process of peer review can be threatening for staff, many of whom may not have had much in the way of work related training or educational opportunities. ${ }^{3}$ Managers or owners of private homes may wish to show to purchasers a commitment to improving quality of care by actively engaging in a quality assurance project, but they may lack the experience and resources to support such a project. The designers of quality assurance packages also face problems-for example, the well known diffculty of deciding what is a good outcome in long term care - and debate about realistic goals. ${ }^{4-7}$ Ideally the consumers-residents and their carers-should be consulted, ${ }^{89}$ but it is often difficult to get useful information from them, especially objective critical opinions. ${ }^{4} 10$

This article aims to convey some of the practical difficulties and benefits of introducing two new quality assurance procedures into two homes for elderly people. By introducing and fully participating in each quality assurance project over a period of two years in each case I was able to witness first hand the difficulties faced by staff and residents and how the problems were dealt with. To further evaluate the projects after completion, I interviewed the staff and residents with whom I had worked and whom, by that stage, I had got to know. My role as full participant, observer, and evaluative interviewer after completion provided unique insights into the worthwhile but sometimes difficult metamorphosis induced by quality assurance. By working with two contemporaneously designed but different projects I was able to compare the pros and cons of each and feed these back to the authors. The lessons learnt from this experience have been usefully incorporated into later revisions of the schemes.

The quality assurance schemes referred to are the CARE scheme (continuous assessment review and evaluation $)^{11}$ designed by the Royal College of Physicians and British Geriatrics Society and IQA (inside quality assurance) ${ }^{12}$ designed by CESSA (Centre for Environmental and Social Studies in Ageing). These organisations set up pilots to assess the effectiveness of their schemes and it was at this stage that I became involved.

\section{The quality assurance packages}

The principle of both these quality assurance packages is to provide a framework for staff to examine everyday practice in the home and the structures, facilities, principles, and philosophies underpinning their daily tasks. The CARE scheme was designed from a health perspective and IQA from a social perspective, reflecting their target sectors-the CARE scheme was aimed at nursing homes and what few National Health Service long term care facilities remain, and IQA at the residential sector. By examining daily routines in the home, aspects that need change can be identified and goals or action plans set. By repeating the process a continuous cycle of peer review is established which promises to be a more powerful and immediate force for change than standard inspection procedures.

\section{INSIDE QUALITY ASSURANCE}

Inside quality assurance requires the formation of a quality group consisting of "insiders"members of staff and residents-and "outsiders"-other interested parties such as doctor, social worker, or relatives. One outsider interviews all staff and residents about six aspects of home life: physical care, choices, expressing feelings, the place as somewhere to live, the way the home is run, and the general atmosphere. The respondent is asked to describe these aspects of residential life and to suggest areas requiring change. The interviewer makes notes, as far as possible quoting the responses verbatim. Inside quality assurance stresses the importance of interviewing all residents, including those deemed confused by staff, and all workers including domestics and maintenance workers. When everybody has been interviewed the responses are collated and sorted into themes. The sorted quotes are presented to the quality group who make an action plan for change. This is fed back to all residents and staff to ensure that it represents a correct interpretation of their views and is then incorporated into a final report which may include information on the home's facilities and philosophy. It may then serve as a consultative document for prospective resi- 
dents and their carers, the local authority inspectorate, or other interested parties.

THE CARE SCHEME

The CARE scheme is a clinical audit package examining nine aspects of geriatric nursing care: preserving autonomy, promoting urinary continence, promoting faecal continence, optimising drug use, managing falls and accidents, preventing pressure sores, environment and equipment, aids and adaptations, and the medical role. Apart from the first domain, preserving autonomy, which considers some quality of life issues such as choice and individuality, these domains deal with healthcare issues. It is generally thought that by improving the quality of health care, the overall wellbeing of residents will be enhanced. Staff choose a domain to audit, complete the relevant individual resident forms, a resident summary form, and facility forms. An audit meeting is then held to discuss aspects needing change. An action plan is recorded indicating the person responsible for each proposal. The process is repeated for each of the domains.

Both IQA and the CARE scheme packages include clear instructions for user homes. In each case the audit cycle is completed by repeating the whole procedure after a suitable interval.

\section{Selecting the homes}

This was not a randomised study. Nor were the homes selected intended to be representative of long term care institutions in the area. We aimed to select homes which had the appropriate mixture of skills and motivation to conscientiously undertake the project. We were helped in doing this by the president of the local Registered Care Homes Association and the Health Authority Registration and Inspection Officer. The projects were therefore tested in the optimal environment for their successful introduction, which meant that the study could more powerfully illustrate the potential benefits and pitfalls.

Both homes were old converted properties, the residential home contained 20 places and the nursing home 28 . In the residential home many residents were demented or had a history of psychiatric illness, whereas the residents in the nursing home were usually both physically and mentally frail. Both homes had a mixture of single and double bedrooms, a choice of communal areas, and a pleasant garden.

STAFF MIX

The residential home was managed by the owner and a registered general nurse (RGN) matron. The owner, who had a second full time professional career nevertheless took a fairly hands on role in the day to day running of the home and was well known to many of the residents. Most of the staff were part time. The nursing home was run by an RGN matron and there was also another RGN and an enrolled nurse. There were fewer part time staff. The owners were somewhat distant and unseen.

In many ways the homes were similar, the main differences being in the role of the owners and the proportion of part time staff. The study took place in the early 1990s. Two cycles of each project were studied, each cycle of IQA taking about nine months from introduction to completion and four months in the case of the CARE scheme.

\section{The IQA experience}

\section{INTRODUCING THE PROJECT}

A steering group including the home owner, the president of the local Registered Care Home Association, a member of CESSA, and myself met in the home to explore the possibility of introducing IQA. Confidentiality was assured. The owner was enthusiastic. It was, however, unfortunate, as will be seen later, that the matron was absent from this initial meeting.

\section{INVOLVING THE STAFF}

The owner arranged an introductory meeting with a group of residents and staff. The group, which would later form the "quality group", included the matron, a selected care assistant, and the two most fit and active residents. These were the insiders. The outsiders included myself, a local social worker, and a relative of one of the residents. It was envisaged that the attending staff and residents would act as representatives and convey the information back to their peers.

The principles of IQA were explained including the need to select an outsider for interviewing all the residents and staff. It was thought most appropriate that I should undertake this time consuming and somewhat daunting task.

Although all members of the group agreed that we should proceed with the project, some comments showed underlying misgivings. One member of staff thought that by undertaking this new initiative she was putting her job at risk. With hindsight I can see that my attempts at reassurance, explaining that the aim was not to test the home but to test the project, were only partially successful.

\section{INTERVIEWING RESIDENTS AND STAFF}

The owner and staff had prepared residents for the forthcoming interviews and consent was confirmed in each case. The package provides a script for the interviewer to explain the procedure to the interviewee assuring anonymity About 20 minutes was suggested per interview. However, by the time the frail elderly respondent has been accompanied, complete with Zimmer frame, into the interview bedroom, the script read, other reassurances and explanations given sometimes to deaf, blind, confused, or simply puzzled residents the procedure usually took at least an hour. With the necessary meal breaks this allowed at most five interviews a day.

The residents seemed to enjoy the opportunity to talk to a listening ear about life in the home and were willing to raise problems and suggest aspects needing change. Most told me that they were very happy there and made to feel "one of the family". It was interesting 
how many residents when asked about "expressing feelings" simply answered, "I don't" or, "I knit" or some similar response perhaps reflecting the culture of their upbringing, but perhaps also indicating lack of opportunity.

Meeting with staff was complicated by shifts and part time work and my limited availability due to hospital duties but eventually meetings were arranged with all day staff. Some night staff were given confidential forms to complete and return. Staff interviews were more straightforward to conduct but a few staff were understandably reluctant to leave their duties particularly if it meant colleagues doing extra work. Staff views of what needed changing often echoed those of the residents. Some staff took the opportunity to tell me that this home was much better than others they had worked in.

\section{USING THE INFORMATION}

During the collation of interview responses themes became apparent. For example, under "physical care" many residents and staff expressed dissatisfaction with bathing arrangements-some residents were required to sit on a wooden bench across the bath instead of getting right into the water. On a flip chart entitled "bathing" quotes pertaining to this issue were listed. This was repeated for all other themes detected. In some instances it was possible to decipher the hidden meaning behind the quote, for instance in response to "expressing feelings" many residents and staff merely replied that staff were very busyperhaps both groups would have appreciated more priority being given to time to stop and chat. The use of residents' quotes to convey a subtext is one of the hallmarks of IQA as it goes some way to overcome the well described reluctance of elderly people to criticise the care they receive. ${ }^{4} 10$

Sometimes it was difficult to know what importance to attach to the comments of severely confused residents, but even these contained glimmers of meaning.

It took several days to sort through all the quotes. These were presented on the flip charts to the quality group in a series of meetings. The powerful impact of residents' quotes became clear. Publically confronted with residents' requests for improved bathing facilities the owner immediately agreed to upgrade these. The group approached creatively the other concerns of residents and staff. At the final meeting a member of staff volunteered to write the project report. ${ }^{13}$ During the second quality assurance cycle a medical student, who had chosen to evaluate the two schemes as her student project, assisted with interviewing.

\section{The CARE scheme experience}

INTRODUCING THE PROJECT

When I met the matron of the nursing home she had already been briefed about the project by the Health Authority Registration and Inspection Officer. We discussed the importance of communicating with residents and staff before introducing the project and ways in which this could be done. These suggestions were carried out by the matron herself.
INVOLVING THE STAFF

The matron selected four senior care assistants for participation in the two weekly audit meetings, which also included the matron and myself. The CARE scheme package allows easy photocopying of the relevant audit forms which were therefore readily provided.

The "personal autonomy" domain was audited first. Each carer in the audit group was allocated four to six residents and completed one resident form for each resident. Some senior care assistants allocated some of their residents to other staff who, therefore, although absent from the audit meetings, became included in the project.

\section{AUDIT MEETINGS}

At the audit meetings the information from the resident forms was collated on to the resident summary form and the facility form was completed. Meetings were generally an enjoyable occasion with tea and biscuits liberally supplied.

On reviewing the results we discussed whether any aspects of care needed change. Staff often replied, "Not really, we already do the best we can." However, at each meeting there were usually one or two positive suggestions for change, which were recorded.

\section{Evaluation interviews}

After completion of both quality assurance schemes I again interviewed staff and residents, this time to hear their views on the projects. A semistructured interview format, provided by Brunel University who were responsible for the national evaluation of IQA, was modified to make it suitable for both schemes. Box 1 shows the main topics covered by these interviews. Staff were interviewed in small groups to foster a feeling of mutual support to encourage frank discussion. Due to limited resources I took notes by hand during the interviews and later analysed and integrated these to form a coherent overview of how the participants perceived the schemes.

\section{Benefits and difficulties} IQA

As might be expected, staff did not tell me face to face their real feelings about the project when it was underway. However, these were disclosed when two members of staff and I attended a prelaunch meeting in London organised by CESSA, which coincided with the early stages of the interviewing. During the meeting staff expressed concern that they had not been sufficiently consulted beforehand and that an "atmosphere" had developed among the staff.

Members of CESSA explained to me that considerable staff anxiety in the early stages of the project is not uncommon but that once the results become known, finding that "nothing awful has been unearthed" staff feel relieved and relax. Some staff later confided how they had thought that they were going to be examined and felt vulnerable about what they perceived as their educational shortcomings. 
Can you tell me how you have been involved in IQA or the CARE scheme?

Initial discussions, plans

Interview and audit forms

On quality group and in audit meetings

Can you tell me a little about your role and how that went?

What did you think about the interviews or questionnaires?

What do you think are the good things or problems about IQA or the CARE scheme?

Would you like to see IQA or the CARE scheme done again?

If so what changes would you like to see?

Can it make residential life better?

Has it changed your practice?

Box 1 Key questions from evaluative interview schedule adapted from Brunel University questionnaire for evaluation of IQA.

To help allay some of these worries midway through the project I arranged a meeting of as many staff and residents as possible to offer further explanation and reassurance. This was found helpful. However, in retrospect it cannot be overestimated how much careful communication is required before introducing such a project. Furthermore, with hindsight, it would have been better if the matron had been included in the steering group or at least consulted before it was decided to introduce the scheme. If her confidence had been gained in the early stages this would have been conveyed to the staff with whom she worked closely.

It has been recognised by CESSA that the interviewer carries much of the anxiety felt by the home and one of the revisions resulting from the pilot was the recommendation that interviewing should be shared between two people to divide the burden.

The evaluation interviews after completion indicated that divisions had arisen among staff. The care worker serving on the quality group had felt particularly pressurised during the first year cycle of IQA. Other staff thought that there was inadequate communication about what was happening during the interview stage. The duration of the project from introduction to publication of the results was criticised. It had been a worrying time, referred to as a silent period. One resident thought that all members of the home should be considered as one group instead of residents and staff. Another criticism was that, in this relatively small home it was easy to decipher "who had said what" and that in some instances the intended anonymity had been lost.

Staff acknowledged and welcomed the sweeping package of improvements that had resulted (box 2). They appreciated the importance of listening to what the residents wanted and their central place in home life. Staff also recognised that the scheme gave them a voice with which to alter the workplace for their own benefit as well as for the residents. These features ensured the staff's wish to repeat the project.

\section{THE CARE SCHEME}

By comparing the results of resident summary forms and facility forms of the first and second audit cycle it was possible to see if improvements had taken place (box 2). The aspect of care most consistently improved was documentation and the development of written policies about aspects of care such as promoting urinary continence. This task, usually undertaken by the matron, was eased by the yellow booklet, High quality long term care for elderly people, which accompanied the CARE scheme package. ${ }^{6}$

The audit meetings provided a forum for discussion about the nine aspects of geriatric nursing covered. The staff in this home seemed to take pride in their role as carers of elderly people and some delighted in increasing their expertise. One hoped to go on to formal nursing training and saw this as an opportunity to get a head start. The educational opportunity afforded by the scheme seemed to boost morale.

The day to day process of caring for confused, incontinent elderly residents is difficult, particularly if there has been little in the way of training. ${ }^{3}$ The CARE scheme gives objectives and rational for some of the most difficult aspects of care, such as faecal incontinence. It may be that in the process of aiming for excellence in these aspects of care the status of the careworker is raised from quasi-domestic to caring professional. Improved staff morale may have spin offs in terms of staff-resident relations which are a key determinant of residential quality of life. ${ }^{14} 15$

Staff had in general enjoyed the audit meetings, but those staff not included in the audit group had considered themselves a little disengaged from the project. Some uncertainty that the scheme could substantially improve the quality of life of the residents was expressed. Some of the forms had been found tedious to complete particularly "environment and equipment". Staff quoted afternoons spent counting washbasins and toilets which they thought would be best left to "a handyman". There was some confusion during "the medical role" audit as there was no systematic medical involvement in the home nor in nursing homes in general in this country (rather, individual residents are listed with one of several local general practitioners).

\section{THE SCHEMES COMPARED}

The differences between IQA and the CARE scheme found in this study cannot necessarily be extrapolated to IQA and the CARE scheme in general. Local issues such as the managerial structure of the homes, the way the packages were introduced, and staff mix were important in shaping the response of the two homes to the packages. In a study like this it is impossible to separate out such home factors from package factors. 


\section{Changes resulting from IQA}

YEAR 1

Bath hoist was purchased so that residents can be lowered into the bath water instead of sitting on a board.

A range of activities including flower pressing, knitting, darts, bingo, occupational therapy, sewing, and making scrap books for local hospitals was introduced.

Furniture layout in the lounge was changed to prevent the unpopular passageway through the middle. This arrangement was given a two month trial.

An area was set aside in the hallway with seating provided, for residents to receive visitors. The possibility of voluntary agencies acting as "listeners" was investigated.

YEAR 2

A Monday to Friday programme of activities and leisure pursuits including a general knowledge quiz, cards, dominoes (large size) and computer games was arranged. One lady resident was taught by the owner how to use a mouse to play computer patience!

An outsider quality group member knew of a local private company with a minibus available for charitable use in the community. Several trips were arranged - to pub happy hours, to Barton on Sea, where residents had a cream tea, and to Southsea, where residents had a seaside snack.

Staff were provided with a uniform which they had requested and which was approved by residents. This seemed to improve staff morale.

A shower was installed as requested by residents.

\section{Changes resulting from the CARE scheme}

\section{PRESERVING AUTONOMY}

Increased documentation in care plan of residents' personal goals and attainments, their preferred forms of address, waking and sleeping times, food, clothing, and activities.

Increased resident participation in choosing from menu.

Increased awareness of patients' rights and dignity.

URINARY INCONTINENCE

Written operational policy for urinary incontinence.

Increased monitoring of the smell of urine.

FAECAL INCONTINENCE

More faecally incontinent residents assessed with regard to promoting faecal continence.

Formation of faecal continence plans for individual residents.

Introduction of a written faecal incontinence policy and increased staff awareness of the issues involved.

OPTIMISING DRUG USE

Written operational drug policy introduced.

Drug indications more often written in care plans.

Routine checking of urea and electrolytes of patients on diuretics.

Less evidence of clinical features suggesting adverse drug reactions.

Drugs which have precautionary interactions or may be contraindicated were discussed by staff and relevant general practitioner.

ENVIRONMENT AND EQUIPMENT

No change as a result of audit.

PREVENTING PRESSURE SORES

Written operational policy for preventing pressure sores was introduced.

Number of pressure sores monitored daily instead of weekly.

Risk assessments monitored daily.

AIDS AND ADAPTATIONS

Staff trained in use of hoists.

MANAGING FALLS AND ACCIDENTS

More thorough assessment of individual falls, including assessment of the environment and management plan to prevent recurrence.

Written policy on the prevention of falls and accidents.

Frequency of falls and action taken as a result of falls monitored.

MEDICAL ROLE

Improved recording of residents' physical and mental condition in care plans.

Box 2 Changes effected as a result of quality assurance packages. 
The introduction of audit invariably causes staff (and residents) an initial period of anxiety contingent with change. This initial discomfort occurred in both homes but more so in the residential home participating in IQA, for several possible reasons, including the lack of involvement of staff in the preparatory stages. Furthermore, in the CARE scheme project staff were in control of the data collection process whereas IQA involved an outsider interviewing all residents and staff in private, which was perhaps more threatening.

On the other hand the process of obtaining residents' quotes makes IQA unique in truly consulting residents about their experience of life in the home. Residents' quotes provided an effective force for change. The range of changes produced by IQA was greater than that produced by the CARE scheme and perhaps had a more immediate effect on residents' lives. However, regular use of the CARE scheme could promote the attainment of predetermined standards of nursing care. Each package has a different emphasis reflecting a different target sector. Home managers can choose the scheme most suitable for their home.

The CARE scheme considered mainly health related issues whereas IQA explored general aspects of residential life. Physical care is one area in which the carer's approach can do much to promote resident wellbeing. ${ }^{16}$ Opportunities for communicating with staff are greatly valued by residents ${ }^{17}$ and these were examined in IQA. The CARE scheme did not consider psychosocial care or recreational activities, which are also essential to residents' quality of life $^{17}$ nor did it consult with the resident-consumers or their relatives. Inclusion of these features in the future version of the CARE scheme would afford a more comprehensive evaluation of residential quality of life.

\section{Concluding discussion}

This article has described my involvement, over a period of nearly three years, in two new quality assurance packages. As both participant-observer and evaluative interviewer, I, with any intrinsic tendency I might have to sympathise with one group or another, was the main research tool. As a geriatrician who would I naturally sympathise withresidents, staff, or both? I hoped I was a fairly neutral observer of a particular social process and that material from several sourcesobservation, interviews, and analysis of audit documentation-provided useful insights into the benefits and problems of introducing quality assurance into long term care homes.

In the light of my experience with these audits I would recommend this approach to improving quality. As a clinician I am aware of the misery that can arise when patients' incontinence, pressure sores, and immobility are inadequately dealt with. The CARE scheme has the potential to prevent such problems by promoting understanding of the principles of high quality geriatric nursing care. At the other end of the range, frail elderly people in the residential sector face the spectre of loss of individuality and loss of control of their environment which can all too easily arise in busy and underresourced homes. Inside quality assurance provides a mechanism to discover the concerns of each resident and to act on these constructively. Staff and residents alike are given their say, and with the completion of each cycle gain confidence that their views count. Ideally this form of audit should become an integral part of everyday long term care for elderly people.

As a geriatrician I would welcome the more widespread uptake of both these schemes. I suspect the resulting improvements in nursing care or social care of residents might in the long term reduce both physical and psychological morbidity in homes. There will always be cases when health breaks down requiring hospital admission but this sometimes unwelcome interruption of care might more often be avoided. A higher profile of quality assurance in homes for elderly people which allow involvement of both residents and their relatives might reduce the fear of patients entering residential care and the guilt and anxiety sometimes felt by relatives. This might ease the process of decision making about the long term care of frail elderly patients for families, general practitioners, and hospital doctors.

Increased uptake of quality assurance might be encouraged by the commissioners of nursing home and residential home places. Perhaps guidance as to the most suitable schemes and some initial support could be provided. I am sure that there are some physicians who care for elderly people who would be willing to give advice and support as required.

In summary, both the CARE scheme and IQA improved quality of residential care in these pilot studies. Consultation with residents and their relatives seemed to add to the power of quality assurance to promote change. Thorough preplanning, careful introduction, and explanation might reduce staff anxiety generated by the introduction of quality assurance.

I thank Leonie Kellaher and Professor John Brocklehurst for inviting me to take part in the IQA and CARE scheme pilots respectively, Katherine Holloway for her assistance in interviewing, and the two homes for their cooperation during the study.

1 National Institute for Social Work. Residential care: a positive choice. London: Her Majesty's Stationery Office, 1988

2 Social Services Inspectorate. Homes are for living in. London: Her Majesty's Stationery Office, 1989.

3 Murphy E. Training for care assistants-new qualifications should raise their status and scope. $B M F 1990 ; 301.506$.

4 Booth T. Home truths. Old people's homes and the outcome of care. Aldershot: Gower, 1985.

5 Evans JG. NHS nursing homes. Age Ageing 1989;18:289Evans

6 Royal College of Physicians and British Geriatrics Society. High quality long-term care for elderly people: guidelines and audit measures. London: Royal College of Physicians, 1992.

7 Millard PH. A case for the development of departments of gerocomy in all district general hospitals: a discussion paper. F $R$ Soc Med 1991;84:731-3.

8 Griffiths R. NHS Management Enquiry. Alexander Fleming House, London: Letter to the Secretary of State for Social Services, 1983.

9 Peace SM, Hall JF, Hamblin GR. The quality of life of the elderly in residential care. London: Survey Research Unit, Polytechnic of North London, 1979. (Research Report No

10 Willcocks D, Peace S, Kellaher L. Private lives in public places. London: Tavistock, 1987. 
11 Research Unit of the Royal College of Physicians. The CARE (continuous assessment review and evaluation) scheme: clinical audit of long-term care of elderly people. London: Royal College of Physicians, 1992.

12 Centre for Environmental and Social Studies in Ageing. Inside quality assurance. London: Polytechnic of North London, 1991

13 Challiner Y. Experience of an inside quality assurance programme in a Southampton rest home. Generations Review, 1993;3:5-6,14.

14 Peace SM, Kellaher LA. A model of residential care: secondary analysis of data from 100 old people's homes. London:
Economic and Social Research Council End of Award Report, 1st ed, March 1985. (Reference number G00232019.)

15 Wilkins D, Hughes B. Residential care of elderly people: the consumers' views. Ageing and Society 1987;7:175201

16 Hughes B, Wilkin P. Physical care and quality of life in residential homes. Ageing and Society 1987;7:399-425.

17 Challiner Y. Measuring and improving quality of life in long term care for the elderly [MD Thesis]. London: University of London, 1995.

\section{Quality in Health Care - http://www.qualityhealthcare.com}

Visitors to the world wide web can now access Quality in Health Care either through the BMJ Publishing Group's home page (http://www.bmjpg.com) or directly by using its individual URL (http:// www.qualityhealthcare.com). There they will find the following:

- Current contents list for the journal

- Contents lists of previous issues

- Members of the editorial board

- Subscribers' information

- Instructions for authors

- Details of reprint services.

A hotlink gives access to:

- BMJ Publishing Group home page

- British Medical Association website

- Online books catalogue

- BMJ Publishing Group books.

The web site is at a preliminary stage and there are plans to develop it into a more sophisticated site. Suggestions from visitors about features they would like to see are welcomed. They can be left via the opening page of the BMJ Publishing Group site or, alternatively, via the journal page, through "about this site". 